\title{
SUPPLY COMPONENT OF BETA VALVE, BLEED VALVE AND PROPELLER REDUCTION GEARBOX ANALYSIS
}

\author{
Ririn Isnawati \\ Program Studi Teknik Dirgantara \\ Sekolah Tinggi Teknologi Adisutjipto \\ Jl. Janti Blok R Lanud Adisutjipto Yogyakarta \\ ririnisnawati97@gmail.com
}

\begin{abstract}
Maintenance is a very important thing to do in order to keep the aircraft in flightworthiness. One form of maintenance activity is the replacement of components that have been damaged (failed). Inventory components cannot be avoided because to get it cannot be done suddenly while for those needs can occur suddenly. Thus, it is necessary to plan the number of component inventories so that smooth production will be maintained. The efforts to solve these problems use the Mean Time Between Removal (MTBR) equation where MTBR is used to determine inventory levels and component replacement scheduling. In addition, the MTBR is a formula or model to determine how much inventory per year will minimize the depletion of inventory in the depository and to estimate component replacement. From the data processing of the G120 TP-A GROB, the number of component inventories in one year is based on the age of components from manufacture (MTBRStandard), among others: 10 Beta Valve Components, 17 Bleed Valve Components, and 13 Propeller Reduction Gearbox Components.
\end{abstract}

Keywords: Beta Valve, Bleed Valve, Propeller Reduction Gearbox, MTBR

\section{Latar Belakang}

Maintenance merupakan hal yang sangat penting untuk dilakukan agar menjaga pesawat tetap dalam keadaan laik terbang. Salah satu bentuk aktivitas maintenance adalah penggantian (replacement) komponen yang telah mengalami kerusakan (failed) [4]. Persediaan (inventory) komponen tidak dapat dihindari karena untuk memperolehnya tidak bisa dilakukan secara mendadak sedangkan untuk kebutuhan tersebut bisa terjadi secara tiba-tiba. Dengan demikian, perlu dilakukan perencanaan jumlah persediaan komponen agar kelancaran produksi tetap terjaga. Dalam jurnal ini, objek komponen yang digunakan penulis antara lain :

a. Komponen Beta Valve: berfungsi untuk mengatur sirkulaasi oli pada propeller yang bertujuan untuk pembalik sudut propeller sehingga didapatkan brake pada saat ground operation.

b. Komponen Bleed Valve: berfungsi untuk mengatur udara dari compressor saat start-up engine, bleed valve bergerak membuka dan menutup berdasarkan tekanan di compressor.

c. Komponen Propeller Reduction Gearbox: berfungi untuk mengurangi dan menaikkan kecepatan putaran power turbine sampai pada kecepatan putar sesuai dengan kebutuhan kerja propeller.

Penulis melakukan penelitian untuk membantu mempermudah pembaca dalam mengetahui persediaan komponen tersebut pada pesawat G120 TP-A GROB sehingga dapat mengurangi tingkat resiko komponen yang kosong. Penelitian dilakukan dengan menggunakan metode Mean Time Between Removal (MTBR). Dimana metode tersebut menjelaskan perhitungan untuk menentukan rata-rata (mean) waktu antara pelepasan (removal) komponen satu ke pelepasan komponen selanjutnya dan menentukan persediaan komponen [2][3]. 


\section{Metodologi Penelitian}

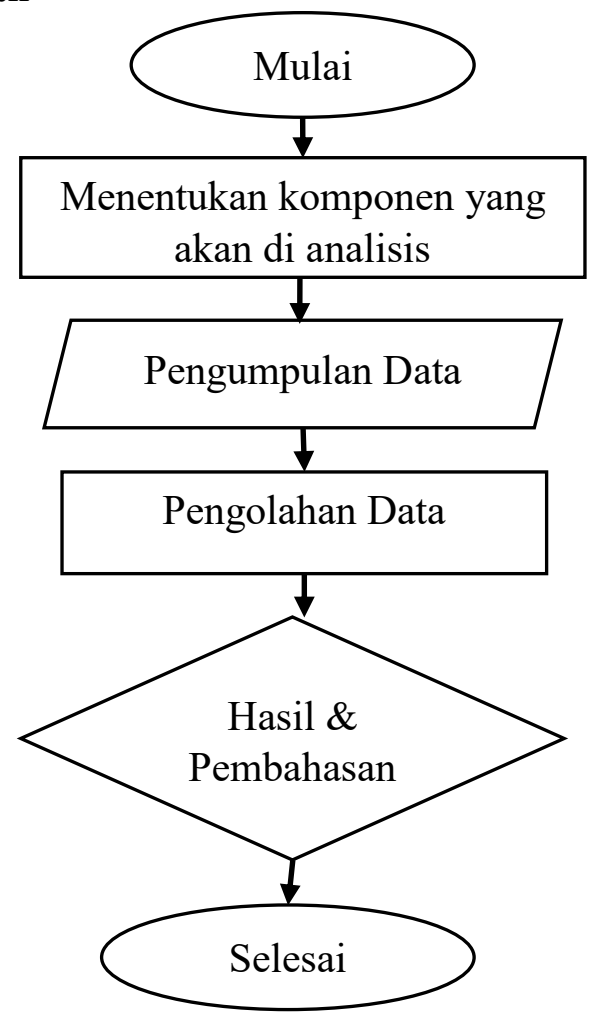

Gambar 1. Alur proses penelitian

Dalam metodologi penelitian ini membahas proses pelaksanaan penelitian dan prinsip kerja system atau kompenen.

\subsection{Proses Pelaksanaan Penelitian}

Proses pelaksanan penelitian sebagaimana diilustrasikan pada Gambar 1. Penjelasan mengenai flowchart penelitian adalah sebagai berikut :

a. Mulai, Penulis menentukan tema dan konsep sebelum menyusun jurnal.

b. Menentukan komponen yang akan digunakan dalam objek penelian, yaitu beta valve, bleed valve, and propeller reduction gearbox pesawat G120 TP-A GROB[3].

c. Pengumpulan Data, Mengelompokkan komponen dari data SKATEK-043.

d. Pengolahan Data, Memasukkan data-data dari masing-masing komponen, yaitu komponen beta valve, bleed valve, and propeller reduction gearbox kedalam rumus Mean Time Between Removal (MTBR).

e. Hasil dan Pembahasan, Data yang sudah di ambil dari SKATEK-043 akan dianalisis menggunakan metode MTBR. Dimana metode tersebut dalam penelitian ini akan digunakan untuk perhitungan rata-rata (mean) waktu antara pelepasan (removal) komponen satu ke pelepasan komponen selanjutnya dan menentukan persediaan komponen dalam waktu satu tahun.

f. Kesimpulan dan Saran, Di peroleh setelah semua data sudah dianalisis.

\subsection{Prinsip Kerja System/ Komponen}

Berikut adalah masing-masing prinsip kerja komponen yang digunakan dalam objek penelitian antara lain : 
a. Komponen Beta Valve

Komponen Beta Valve terdapat pada gambar 2 di pasang di dalam poros engine, beta valve rods memanjang ke depan melalui pusat poros propeller dan keluar diluar bagian depan piston. Sedangkan beta valve rods memanjang keluar melalui bagian belakang gearbox engine dimana terhubung ke engine-propeller control system [5].

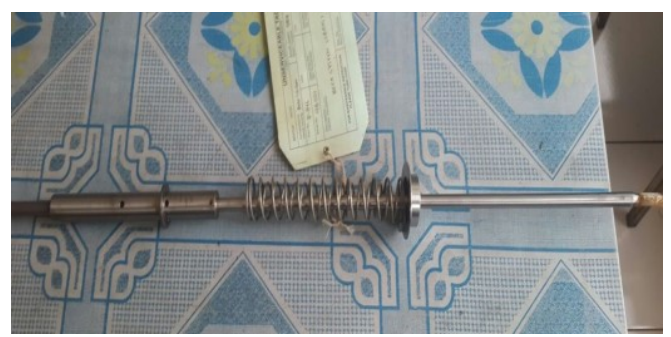

Gambar 2 Komponen Beta Valve

b. Komponen Bleed Valve

Komponen Bleed Valve sesuai dengan gambar 3 terbuka pada saat kondisi di compressor bertekanan rendah dan menutup saat tekanan didalam compressor sudah stabil, untuk mencegah terjadinya stall compressor.

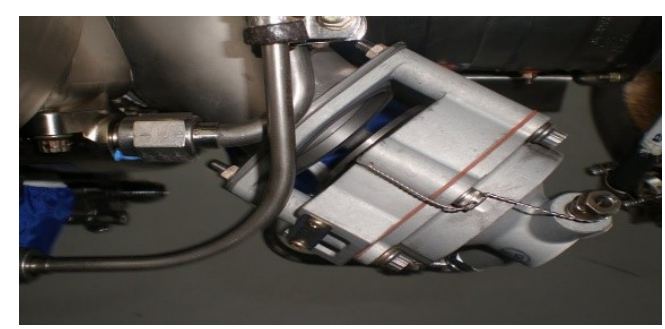

Gambar 3 Komponen Bleed Valve

c. Komponen Propeller Reduction Gearbox

Cara kerja Propeller Reduction Gearbox adalah putaran shaft power turbine langsung terkoneksi ke gerigi reduction gearbox, sehingga gerigi reduction gearbox tersebut berputar. Dibawah ini gambar 4 adalah komponen propeller reduction gearbox.

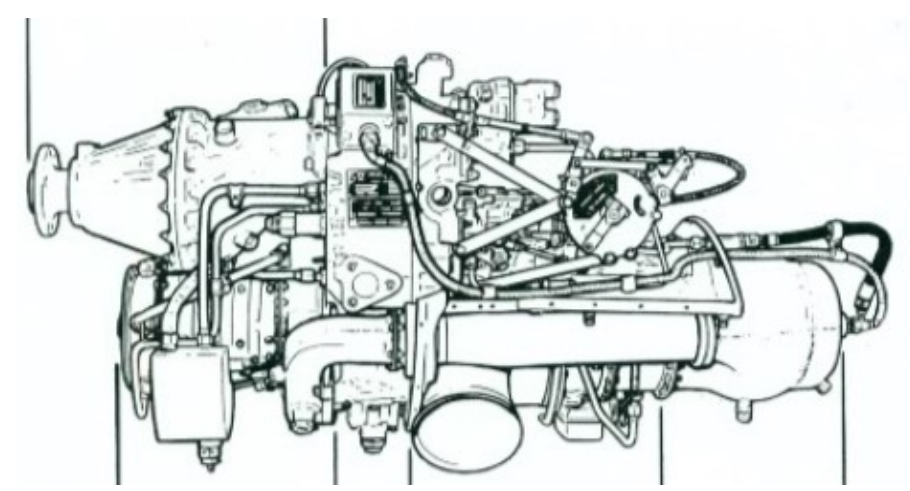

Gambar 4 Komponen Propeller Reduction Gearbox

Sumber : Aircraft Flight manual Pesawat Grob 


\section{Hasil dan Pembahasan}

Data-data yang berhubungan dengan tema dan konsep dikelompokkan. Setelah itu dilakukan analisis. Data Spesifikasi dari Pesawat G120 TP-A GROB dapat dilihat pada table 1

Tabel 1. Aircraft General Specifications

\begin{tabular}{|c|c|}
\hline \multicolumn{2}{|l|}{ 1. Overall Dimentions } \\
\hline Overall length & $8.416 \mathrm{~m}$ \\
\hline Overall span & $10.258 \mathrm{~m}$ \\
\hline Overall height & $2.722 \mathrm{~m} 8.93 \mathrm{ft}$ \\
\hline \multicolumn{2}{|l|}{ 2. Wing } \\
\hline Ref area & $13.52 \mathrm{~m} 2$ \\
\hline Ref span & $1038 \mathrm{~m}$ \\
\hline LEMAC & $2.329 \mathrm{~mm} \mathrm{QE}$ \\
\hline Aspect ratio & Appr. 7.86 \\
\hline Dihidral & $3^{\circ}$ \\
\hline Angle of incidence & $0^{\circ}$ \\
\hline Flap deflectin/ take off & $20^{\circ}$ \\
\hline Flap deflectin/landing & $40^{\circ}$ \\
\hline Maximum falp detection & $60^{\circ}$ \\
\hline \multicolumn{2}{|l|}{ 3. Horizontal tail } \\
\hline Ref.area & $3.040 \mathrm{~m} 2$ \\
\hline Overall span & $3.800 \mathrm{~m}$ \\
\hline Chord & $1.000 \mathrm{~m}$ root $0.600 \mathrm{~m}$ tip \\
\hline Airfoil & NACA $64-101$ \\
\hline \multicolumn{2}{|l|}{ 4. Vertical tail } \\
\hline Ref.area & $2.038 \mathrm{~m} 2$ \\
\hline Chord (mean) & $1.18 \mathrm{~m}$ \\
\hline Airfoil & NACA 64009 \\
\hline \multicolumn{2}{|l|}{ 5. Control surface } \\
\hline Aileron surface area each side & $0.366 \mathrm{~m} 2$ \\
\hline Aileron span each side & $1.54 \mathrm{~m}$ \\
\hline Elevator area & $0.69 \mathrm{~m} 2$ \\
\hline Elevator span total & $2.46 \mathrm{~m}$ \\
\hline Rudder area & 0.857 \\
\hline Overall rudder span & $1.73 \mathrm{~m}$ \\
\hline \multicolumn{2}{|l|}{ 6. Fuselage } \\
\hline Overall length & $8.416 \mathrm{~m}$ \\
\hline Maximum width & $1.303 \mathrm{~m}$ \\
\hline \multicolumn{2}{|l|}{ 7. Internal dimension } \\
\hline $\begin{array}{l}\text { Cockpit length including passenger and } \\
\text { baggage }\end{array}$ & $2.495 \mathrm{~m}$ \\
\hline Cockpit width & $1.245 \mathrm{~m}$ \\
\hline Cockpit floor to roof & $1.19 \mathrm{~m}$ \\
\hline Seat pan to roof front/rear & $0.97 \mathrm{~m}$ \\
\hline Baggage area volume max & $0.22 \mathrm{~m} 2$ \\
\hline \multicolumn{2}{|l|}{ 8. Engine } \\
\hline Type & turbo-propeller Allison 250-B17F \\
\hline
\end{tabular}




\begin{tabular}{|l|l|}
\hline Manufacturer & Roll Royce coporation \\
\hline Engine model no & $250-\mathrm{B} 17 \mathrm{~F}$ \\
\hline Rated horsepower & $450 \mathrm{SHP}$ \\
\hline Propeller speed & $2030 \mathrm{RPM}$ \\
\hline Propeller weight & $212 \mathrm{lbs} / 96,2 \mathrm{~kg}$ \\
\hline Compressor stages & 4 axial, 1 radial \\
\hline Turbin stages & $\begin{array}{l}2 \text { stage gas producer, 2 stage power } \\
\text { turbin }\end{array}$ \\
\hline 9. Propeller & MT-Propeller \\
\hline Propeller manufacturer & $2.10 \mathrm{~m}$ \\
\hline Diameter & \\
\hline 10. Fuel & 360 liter / 288 kg / 635 lb \\
\hline Capacity & \\
\hline 11. Oil & 15 liter \\
\hline Oil tank capacity (max) & 12 liter \\
\hline Oil tank capacity (min) & MIL-23699 \\
\hline Oil specilication & \\
\hline
\end{tabular}

Pada tabel 2 merupakan data umur komponen berdasarkan manufaktur (TBO) yang diperoleh dari Tata Usaha Teknik (TUT) SKATEK-043.

Tabel 2. Data Umur Komponen Berdasarkan Manufaktur

\begin{tabular}{|c|c|c|c|}
\hline No & Nama Komponen & Part Numberm(P/N) & TBO(Jam) \\
\hline 1 & Beta valve & P-846 & 2500 \\
\hline 2 & Bleed Valve & 230732078 & 1500 \\
\hline 3 & Propeller Reduction Gearbox & 2303380 & 2000 \\
\hline
\end{tabular}

Tabel 2 menjelaskan bahwa TBO masing- masing komponen berbeda-beda yaitu Beta valve dengan TBO 2500 jam, Bleed Valve dengan TBO 1500 sedangkan Propeller Reduction Gearbox dengan TBO 2000 jam. Setiap pergantian komponen selalu berdasarkan dengan jam terbang maka dari manufaktur selalu meyediakan komponen jumlah dalam satu tahun .

Tabel 3 adalah data yang menjelaskan utilisasi dari jam terbang pesawat G120 TP-A Grob yang terdapat di SKATEK-043

Tabel 3 Data Utilisasi Jam Terbang Pesawat G120 TP-A Grob Serviceable

\begin{tabular}{|c|c|c|c|}
\hline No & Pesawat & Bulan & Durasi Jam Terbang \\
\hline 1 & LD-1203 & & 1393,17 \\
\hline 2 & LD-1205 & & 1514,25 \\
\hline 3 & LD-1206 & \multirow{4}{*}{$\begin{array}{c}\text { Januari 2018 s.d } \\
\text { Desember 2018 }\end{array}$} & 1515,25 \\
& LD-1207 & 1114,42 \\
\hline 5 & LD-1209 & 681,58 \\
\hline 6 & LD-1211 & & 417,5 \\
\hline 7 & LD-1212 & & 1551,83 \\
\hline
\end{tabular}




\begin{tabular}{|c|c|c|}
\hline 8 & LD-1213 & 1354,75 \\
\hline 9 & LD-1214 & 1580,92 \\
\hline 10 & LD-1215 & 1032 \\
\hline 11 & LD-1216 & 1540,83 \\
\hline 12 & LD-1217 & 1065,83 \\
\hline 13 & LD-1218 & 1582,42 \\
\hline 14 & LD-1219 & 676,75 \\
\hline 15 & LD-1220 & 442,92 \\
\hline 16 & LD-1221 & 1587,1 \\
\hline 17 & LD-1222 & 1144,83 \\
\hline 18 & LD-1223 & 1023,75 \\
\hline 19 & LD-1224 & 1075,75 \\
\hline 20 & LD-1225 & 580,33 \\
\hline 21 & LD-1226 & 572,5 \\
\hline 22 & LD-1227 & 611,58 \\
\hline 23 & LD-1228 & 700,42 \\
\hline 24 & LD-1229 & 723,75 \\
\hline 25 & LD-1230 & 660,25 \\
\hline \multicolumn{2}{|c|}{ Total durasi jam terbang $\left(\sum X_{i}\right)$} & 26144,68 \\
\hline \multicolumn{2}{|c|}{ Rata-rata (mean) durasi jam terbang/tahun $(\bar{X})$} & 1045,79 \\
\hline \multicolumn{2}{|c|}{ Rata-rata (mean) durasi jam terbang/hari $(\bar{X})$} & 2,90 \\
\hline
\end{tabular}

Sumber : Data utilisasi jam terbang pesawat G120 TP-A Grob - DANWINGDIK TER

(SKADIK 101)

Dari analisis table di atas mendapatkan rata-rata durasi jam terbang 2,90 jam/hari,sehingga MTBR $\left._{\text {Standard}}\right)$ antara lain: 10 komponen Beta Valve, 17 komponen Bleed Valve, dan 13 komponen Propeller Reduction Gearbox

\section{Kesimpulan}

Dari pengolahan data yang telah dilakukan dapat disimpulkan bahwa, jumlah persediaan komponen dalam satu tahun berdasarkan umur komponen dari manufaktur (MTBR Standard$_{\text {}}$ ) antara lain : 10 komponen Beta Valve, 17 komponen Bleed Valve, dan 13 komponen Propeller Reduction Gearbox. 


\section{Daftar Pustaka}

[1] Permatasari, Devi Yuliana, 2019, “Analisis Keandalan dan Persediaan Komponen Beta Valve, Bleed Valve, dan Propeller Reduction Gearbox Pesawat G120 TP-A GROB (SKATEK) Menggunakan Perhitungan MTBF, MTTR, Inhernt Availability dan MTBR", Perpustakaan STTA, Yogyakarta.

[2] Aircraft Flight Manual,Pesawat G120 TP-A Grob, Skadron Teknik (SKATEK-043) Lamud Adisutjipto, Yogyakarta.

[3] Maintenance Training Manual, Pesawat G120 TP-A Grob, Skadron Teknik (SKATEK043) Lanud Adisutjipto, Yogyakarta

[4] Pujawan, I Nyoman. 2017, "Supply Chain Management Edisi 3", Guna Widya, Surabaya.

[5] Mattingly, Jack. D. 2006. Elements Of Propulsion : Gas Turbine and Rockets. AIAA Education Series.

[6] Mallinge, Yannick. 2016, "Safety First", The Airbus Safety Magazine 